\title{
Kinerja Spectrum Sensing Dengan Metode Cyclostationary Feature Detector Pada Radio Kognitif
}

\author{
HENDRY CAHYO H. ${ }^{1}$, DWI ARYANTA ${ }^{1}$, NASRULLAH ARMI ${ }^{2}$ \\ 1. Teknik Elektro Institut Teknologi Nasional \\ 2. Lembaga Ilmu Pengetahuan Indonesia \\ Email : hendryhardiyanto@yahoo.com
}

\begin{abstract}
ABSTRAK
Perkembangan dalam dunia telekomunikasi nirkabel terutama spektrum frekuensi adalah hal yang perlu mendapatkan perhatian penting. Spektrum frekuensi merupakan sumber daya yang terbatas, penggunaannya harus dilakukan secara efisien dan se-maksimal mungkin. Penelitian ini membahas teknik spectrum sensing pada radio kognitif untuk menghadapi masalah keterbatasan penggunaan spektrum frekuensi. Radio kognitif merupakan sistem radio cerdas yang bisa mengatur parameternya seperti frekuensi kerja, daya pancar, dan skema modulasi secara optimal dalam melakukan proses komunikasi. Spectrum sensing merupakan teknik untuk memaksimalkan penggunaan spektrum frekuensi. Penelitian ini membandingkan kinerja metode cyclostationary feature detection dan metode energy detection pada teknik spectrum sensing menggunakan software matlab sehingga dapat diketahui bahwa kinerja cyclostationary feature detection untuk nilai Pd $=0,85$ lebih handal sebesar 0,2 untuk fungsi probability of false dan lebih handal sebesar $2 d B$ untuk fungsi signal to noise ratio daripada energy detection.
\end{abstract}

Kata kunci: radio kognitif, spectrum sensing, cyclostationary feature detection, energy detection, probability of false alarm.

\begin{abstract}
Developments in the world of wireless telecommunications specially frequency spectrum is an important thing to get attention. Frequency spectrum is afinite resource, its use must be efficiently and as maximum as possible. This study discuss the technique of spectrum sensing in cognitive radio to faces the problem using restrictiveness of frequency spectrum. Cognitive radio is a smart radio system that can adjust its parameters like work frequency, emission power, and modulation scheme are optimal in the communication process. Spectrum sensing is a technique to maximize the use of the frequency spectrum. This study compared performance of cyclostationary feature detection methodh with energy detection methodh in spectrum sensing technique using matlab software so ascertainable that cyclostationary feature detection performance for $P d$ value 0,85 better about 0,2 for probability of false alarm function and better about $2 d B$ for signal to noise ratio function than energy detection.
\end{abstract}

Keywords : cognitif radio, spectrum sensing, cyclostationary feature detection, energy detection, probability of false alarm. 


\section{PENDAHULUAN}

Dalam dunia telekomunikasi nirkabel (Wireless Communications) spektrum frekuensi adalah hal yang mendapatkan perhatian penting, karena melalui spektrum inilah data bisa dikirimkan. Karena spektrum sangat penting dan merupakan sumber daya (resource) yang terbatas, penggunaannya harus dilakukan secara efisien dan se-maksimal mungkin. Di sisi yang lain, penggunaan spektrum secara maksimal sering kali bertemu dengan kondisi negatif yang akan muncul karenanya, yaitu membesarnya interferensi antar pengguna saluran telekomunikasi ini. Maka latar belakang dalam penelitian ini adalah bagaimana cara untuk memanfaatkan spektrum frekuensi yang belum maksimal penggunaannya seperti saat ini agar dapat dipakai untuk melakukan proses komunikasi. Dari latar belakang tersebut maka akan muncul beberapa permasalahan pemakaian spektrum frekuensi yang belum efisien dan cara untuk menentukan pengguna utama atau Primary User (PU) serta akurasi deteksi sinyal pengguna utama (PU). Dengan adanya permasalahan tadi dalam penelitian ini akan dilakukan simulasi menggunakan software matlab sehingga dapat menggali secara lebih dalam metode detection yang ada di spectrum sensing.

Spectrum sensing adalah proses melakukan pengukuran pada bagian dari suatu spektrum dan berdasarkan dari data yang telah diukur sehingga akan dapat membuat keputusan terkait penggunaan spektrum tersebut. Primary User (PU) atau pengguna utama adalah alat komunikasi (device) yang memiliki sebuah frekuensi tertentu, misalnya primary user merupakan sebuah perangkat radio FM maka primary user tersebut akan memancarkan sinyal dengan frekuensi sebesar $88-108 \mathrm{MHz}$. Secondary User (SU) atau pengguna sekunder adalah alat komunikasi (device) yang dapat mengakses sebuah frekuensi berlisensi untuk dapat melakukan proses komunikasi yang disebut dengan radio kognitif. Secondary User (SU) ini dapat menggunakan sebuah frekuensi berlisensi tertentu asalkan tidak mengganggu proses komunikasi dari Primary User(PU).

Pada tahun 2012, Pradeep Kumar (Verma, 2012) malakukan penelitian tentang perbandingan tiga teknik spectrum sensing terhadap fungsi Probability of Detection (Pd) dan Signal to Noise Ratio (SNR). Dari penelitian tersebut didapatkan hasil bahwa kinerja dari metode Cyclostationary Feature Detection lebih handal dari metode Energy Detection dan Matched Filter untuk nilai SNR tinggi ataupun nilai SNR rendah. Penelitian berikutnya pada tahun 2013, Hyung Seok dkk. (Kim, 2013) melakukan penelitian tentang perbandingan tiga teknik spectrum sensing terhadap fungsi Probability of Detection (Pd) dan Probability of False Alarm (PFA). Dari penelitian tersebut didapatkan hasil bahwa kinerja dari metode Cyclostationary Feature Detection lebih handal daripada metode Energy Detection dan Matched Filter Detection. Sedangkan untuk kinerja dari Energy Detection dan Matched Filter Detection hampir memiliki performa yang sama berdasar fungsi PFA.

Berdasarkan beberapa penelitian diatas maka penelitian ini akan menggabungkan ketiga fungsi yang digunakan sebagai parameter sekaligus agar mendapatkan hasil yang lebih lengkap dan akurat. Namun metode spectrum sensing yang diperbandingkan hanya 2 saja yaitu Cyclostationary Feature Detection dan Energy Detection. Energy Detection adalah sebuah metode deteksi yang mendeteksi sinyal primer berdasarkan pada energy sensing. Metode ini sangat sederhana dan tidak memerlukan syarat (jenis modulasi atau jenis sinyal pembawanya). Cyclostationary Feature Detection merupakan pemanfaatan periode waktu tertentu dari sinyal primer yang diterima untuk mengenal adanya pengguna primer. Probability of Detection (Pd) adalah waktu selama Primary User (PU) terdeteksi sedangkan. Probability of False Alarm (PFA) adalah probabilitas atau kemungkinan dari algoritma sensing melakukan kesalahan deteksi keberadaan Primary User (PU) yang sebenarnya tidak aktif. 


\section{METODOLOGI PENELITI AN}

\subsection{Sistem Kerja}

Sebelum melakukan simulasi terlebih dahulu dilakukan perencanaan terhadap apa yang akan dilakukan dalam penelitian ini.

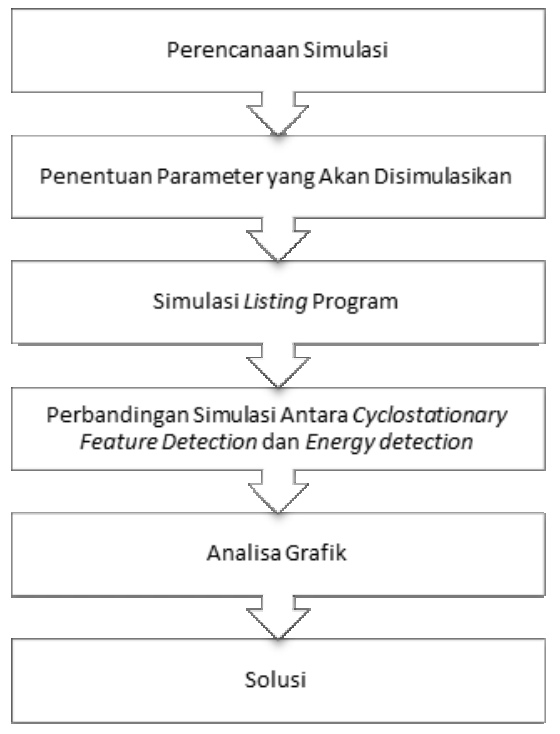

Gambar 1. Sistem Kerja

Dari gambar 1 dapat diketahui sistem kerja dalam melakukan penelitian ini. Yang pertama dilakukan yaitu merencanakan simulasi dengan menggunakan software matlab R2012a (7.14.0.734). Software tersebut digunakan karena mampu menampilkan grafik secara jelas serta telah terdapat fitur - fitur yang dapat digunakan untung melakukan simulasi spectrum sensing. Parameter yang digunakan ada 3 yaitu Signal to Noise Ratio (SNR), Probability of Detection (Pd) dan Probability of False Alarm (PFA). Kemudian mulai membuat listing program untuk kemudian hasilnya diperbandingkan secara grafik antara Cyclostationary Feature Detection dan Energy Detection. Setelah dianalisa serta hasilnya diperbandingkan dengan berbagai teori yang ada serta berbagai penelitian yang telah dilakukan terdahulu maka didapatkan solusi untuk menjawab berbagai macam pertanyaan yang muncul sebelum penelitian ini dilakukan.

\subsection{Perencanaan Simulasi}

Simulasi yang dilakukan dalam penelitian ini ada yaitu mengetahui kinerja Cyclostationary Feature Detection itu sendiri. Setelah itu kinerja dari Cyclostationary Feature Detection akan dibandingkan dengan kinerja Energy Detection untuk fungsi SNR dan PFA menggunakan fungsi Pd sebagai variabel tetapnya. Pada proses simulasi kinerja Cyclostationary Feature Detection ini akan ditampilkan grafik dari kinerja Cyclostationary Feature Detection dalam berbagai macam nilai Signal to Noise Ratio (SNR) dimulai dari SNR $=-15 \mathrm{~dB}$ hingga SNR = $15 \mathrm{~dB}$ dengan selisih sebesar $5 \mathrm{~dB}$ untuk setiap grafiknya. Parameter yang digunakan yaitu fungsi Probability of Detection (Pd) untuk sumbu $Y$ dan fungsi Probability of False Alarm (PFA) untuk sumbu $X$. Tujuan dari simulasi ini adalah untuk dapat mengetahui performa kinerja dari Cyclostationary Feature Detection pada beberapa nilai dB dimulai dari nilai SNR yang kecil menuju nilai SNR yang lebih besar.

Pada proses simulasi kinerja Cyclostationary Feature Detection Vs. Energy Detection dengan fungsi PFA ini akan ditampilkan grafik dari kinerja Cyclostationary Feature Detection dibandingkan dengan grafik kinerja dari Energy Detection dalam berbagai macam nilai Signal 
to Noise Ratio (SNR) dimulai dari SNR $=-15 \mathrm{~dB},-10 \mathrm{~dB},-5 \mathrm{~dB}, 0 \mathrm{~dB}, 5 \mathrm{~dB}, 11 \mathrm{~dB}$, dan 12 $\mathrm{dB}$. Parameter yang digunakan yaitu fungsi Probability of Detection (Pd) untuk sumbu $\mathrm{Y}$ dan fungsi Probability of False Alarm (PFA) untuk sumbu X. Tujuan dari simulasi ini adalah untuk dapat mengetahui performa kinerja dari Cyclostationary Feature Detection dibandingkan dengan performa kinerja dari Energy Detection sehingga dapat ditentukan mana yang lebih baik. Selain itu juga dalam simulasi ini dapat juga ditentukan nilai SNR minimum yang dibutuhkan oleh Cyclostationary Feature Detection mencapai Probability of Detection (Pd) sebesar $100 \%$ untuk Probability of False Alarm (PFA) sebesar $0 \%$.

Pada proses simulasi ini akan ditampilkan grafik dari kinerja Cyclostationary Feature Detection dibandingkan dengan grafik kinerja dari Energy Detection namun dilihat dari fungsi Signal to Noise Ratio (SNR) sebagai sumbu X dan fungsi Probability of Detection (Pd) sebagai sumbu Y. Untuk simulasi ini menggunakan nilai Probability of False Alarm (PFA) sebesar 0,0001 . Nilai PFA tersebut digunakan karena merupakan nilai yang biasanya dipakai sebagai acuan agar hasil grafisnya dapat terbaca dengan baik. Tujuan dari simulasi ini adalah untuk mengetahui perbandingan kinerja antara Cyclostationary Feature Detection dengan Energy Detection sehingga dapat diketahui mana yang memiliki kinerja yang lebih baik berdasarkan fungsi Signal to Noise Ratio (SNR).

\subsection{Diagram Alir Simulasi}

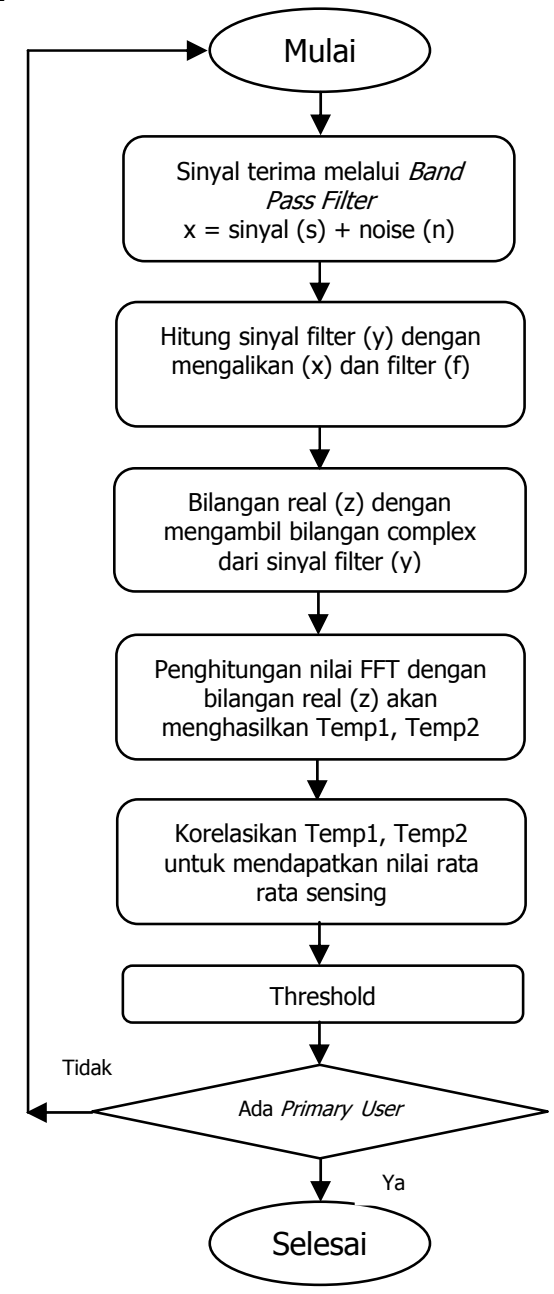

Gambar 2. Diagram Alir Simulasi Cyclostationary Feature Detection 


\section{HASI L DAN PEMBAHASAN}

\subsection{Kinerja Cyclostationary Feature Detection}

Gambar berikut ini akan menunjukkan grafik kinerja dari Cyclostationary Feature Detection dengan berbagai nilai Signal to Noise Ratio (SNR).

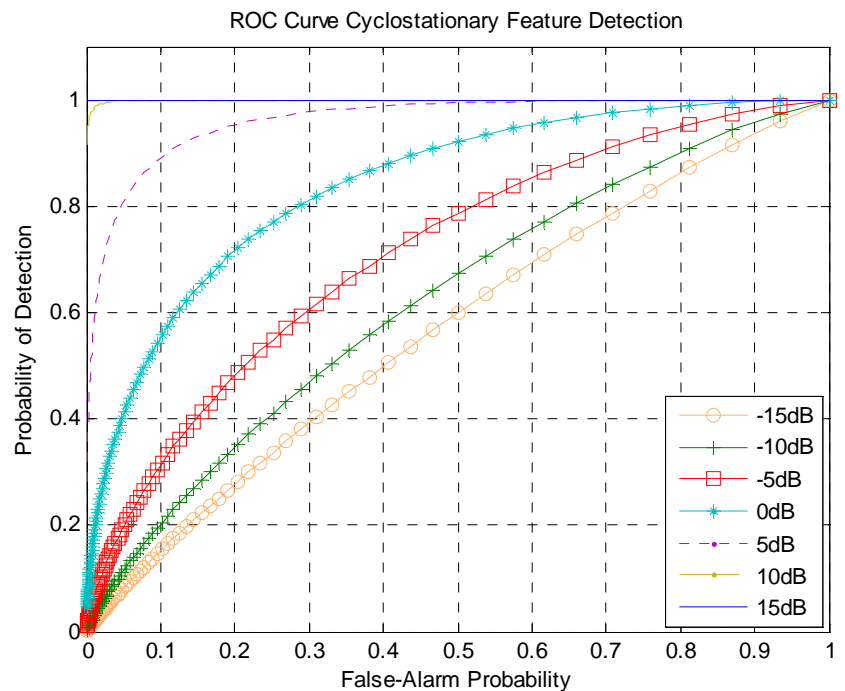

Gambar 3. Grafik Kinerja Cyclostationary Feature Detection

Dari gambar 3 dapat diketahui kinerja dari Cyclostationary Feature Detection mulai dari nilai SNR $=-15 \mathrm{~dB}$ sampai SNR $=15 \mathrm{~dB}$ dengan selisih setiap grafiknya sebesar $5 \mathrm{~dB}$. Seperti yang terlihat pada gambar 3 kinerja dari Cyclostationary Feature Detection sangat dipengaruhi oleh besarnya nilai SNR. Sebagai contoh perbandingan kita akan mengambil grafik dengan nilai SNR $=0 \mathrm{~dB}$ dan grafik dengan nilai SNR $=5 \mathrm{~dB}$. Grafik dengan nilai SNR $=0 \mathrm{~dB}$ (biru muda) untuk mencapai nilai Probability of Detection (Pd) berkisar 0,99 membutuhkan nilai Probability of False Alarm (PFA) sebesar 0,87. Sedangkan untuk grafik dengan nilai SNR $=5 \mathrm{~dB}$ untuk mencapai nilai Probability of Detection (Pd) sebesar 0.99 membutuhkan nilai Probability of False Alarm (PFA) sebesar 0,53. Dari hasil pembacaan grafik tersebut dapat diketahui bahwa kinerja Cyclostationary Feature Detection untuk nilai $\mathrm{SNR}=5 \mathrm{~dB}$ lebih baik daripada nilai SNR $=0 \mathrm{~dB}$. Karena untuk Cyclostationary Feature Detection dengan nilai SNR $=5 \mathrm{~dB}$ membutuhkan kemungkinan error (kesalahan) dengan presentase yang lebih kecil untuk mencapai Probability of Detection (Pd) sebesar 1 daripada Cyclostationary Feature Detection dengan nilai SNR $=0 \mathrm{~dB}$. Sehingga dapat disimpulkan bahwa semakin tinggi nilai SNR dari Cyclostationary Feature Detection maka kinerjanya akan semakin handal juga.

\subsection{Kinerja Cyclostationary Feature Detection Vs. Energy Detection dengan Fungsi PFA}

Gambar berikut ini akan menunjukkan beberapa grafik kinerja dari Cyclostationary Feature Detection dibandingkan dengan grafik kinerja dari Energy Detection dengan nilai SNR yang berbeda. Perbandingan grafik kinerja tersebut dimaksudkan agar dapat mengetahui metode spectrum sensing yang bekerja dengan lebih baik untuk nilai SNR tinggi dan nilai SNR rendah serta akan diketahui juga kinerja minimum untuk metode Cyclostationary Feature Detection dalam melakukan proses sensing. Pada perbandingan grafik kinerja berikut menggunakan nilai PFA sebesar 0,0003 karena nilai tersebut tidak terlalu tinggi dan tidak terlalu rendah untuk proses simulasi sehingga akan menunjukkan hasil yang maksimal. 


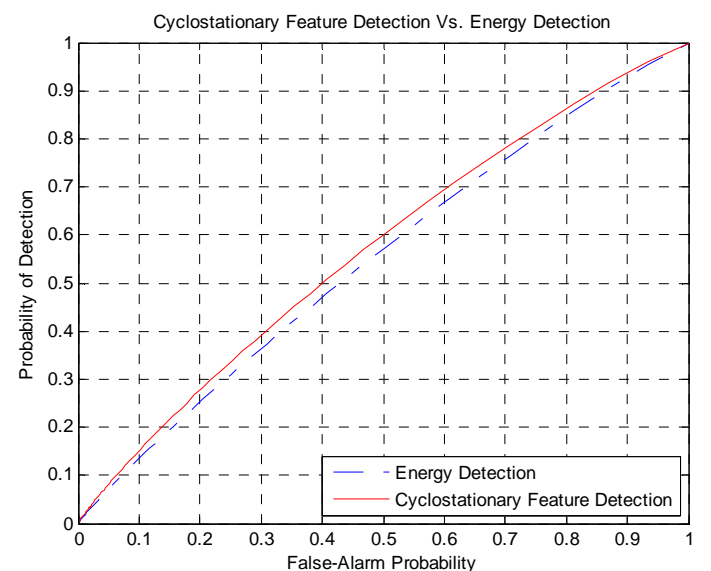

Gambar 4. Kinerja dengan SNR $=-15 \mathrm{~dB}$

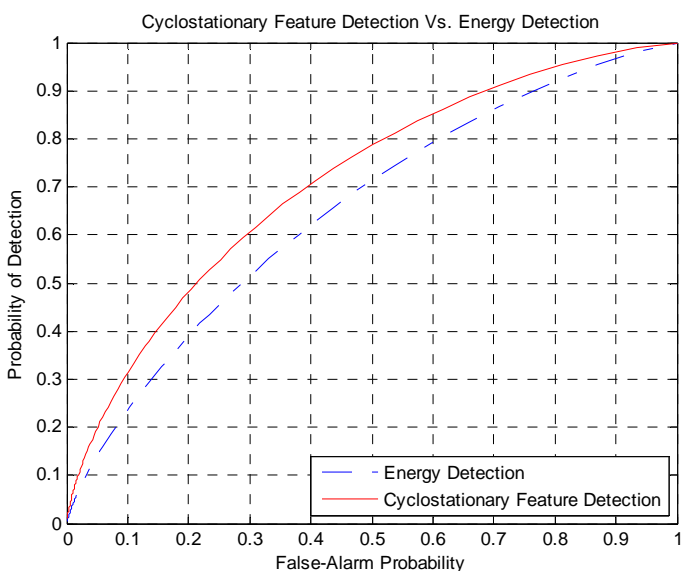

Gambar 5. Kinerja dengan SNR $=-5 \mathrm{~dB}$

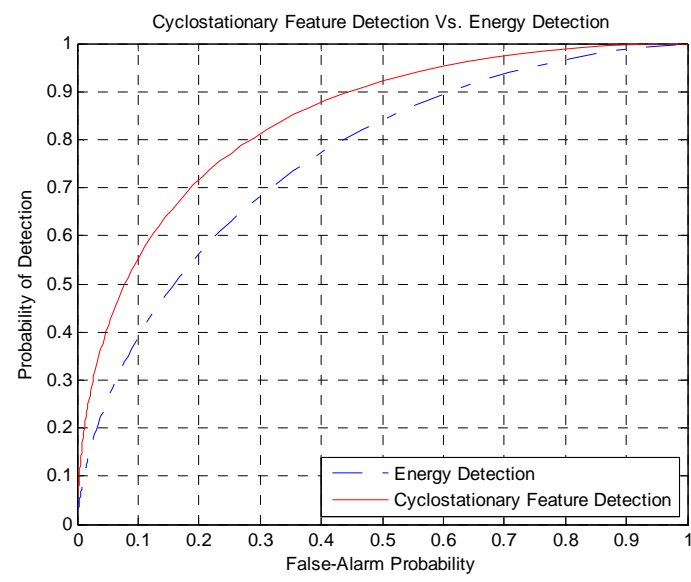

Gambar 6. Kinerja dengan SNR $=0 \mathrm{~dB}$

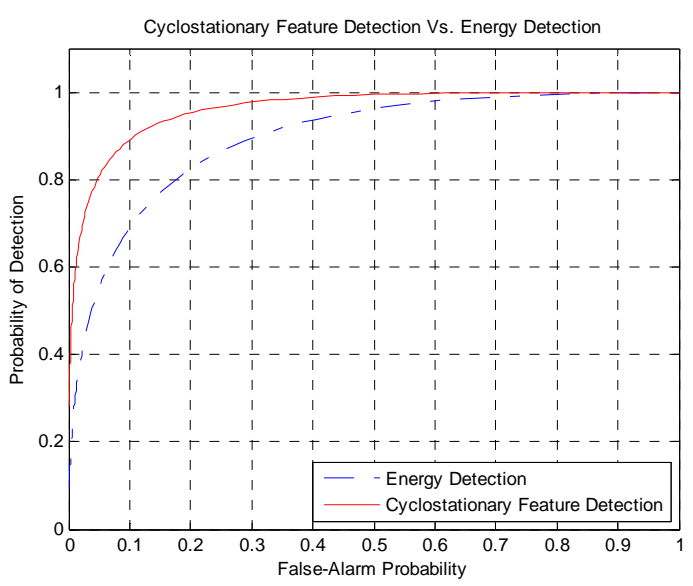

Gambar 7. Kinerja dengan SNR $=5 \mathrm{~dB}$

Dari gambar 4 sampai dengan gambar 7 dapat diketahui bahwa kinerja dari Cyclostationary Feature Detection selalu lebih baik daripada kinerja dari Energy detection. Sebagai contoh akan diambil nilai yang rendah SNR $=-15 \mathrm{~dB}$ dan nilai yang tinggi SNR $=5 \mathrm{~dB}$. Untuk grafik nilai SNR $=-15 \mathrm{~dB}$, Cyclostationary Feature Detection memiliki kinerja yang lebih baik daripada Energy Detection. Seperti pada gambar 4. untuk Probability of False Alarm (PFA) dengan nilai 0,5, kinerja Cyclostationary Feature Detection sudah mencapai 0,6 sedangkan kinerja dari Energy Detection baru mencapai 0,57. Walaupun hanya memiliki selisih sebesar 0,03 namun hal tersebut telah menunjukkan bahwa kinerja Cyclostationary Feature Detection lebih baik daripada kinerja Energy Detection pada nilai SNR $=-15 \mathrm{~dB}$. Kemudian untuk grafik nilai SNR $=5 \mathrm{~dB}$, Cyclostationary Feature Detection memiliki kinerja yang lebih baik daripada Energy Detection. Seperti pada gambar 7 untuk Probability of False Alarm (PFA) dengan nilai 0,5, kinerja Cyclostationary Feature Detection sudah mencapai 0,99 sedangkan kinerja dari Energy Detection baru mencapai 0,96. Dengan selisih sebesar 0,03 menunjukkan bahwa kinerja Cyclostationary Feature Detection lebih baik daripada kinerja Energy Detection pada nilai SNR $=5 \mathrm{~dB}$. Dari dua perbandingan tersebut maka dapat disimpulkan bahwa kinerja dari Cyclostationary Feature Detection selalu lebih baik daripada kinerja dari Energy Detection pada keadaan nilai SNR yang rendah ataupun pada keadaan nilai SNR yang tinggi. 


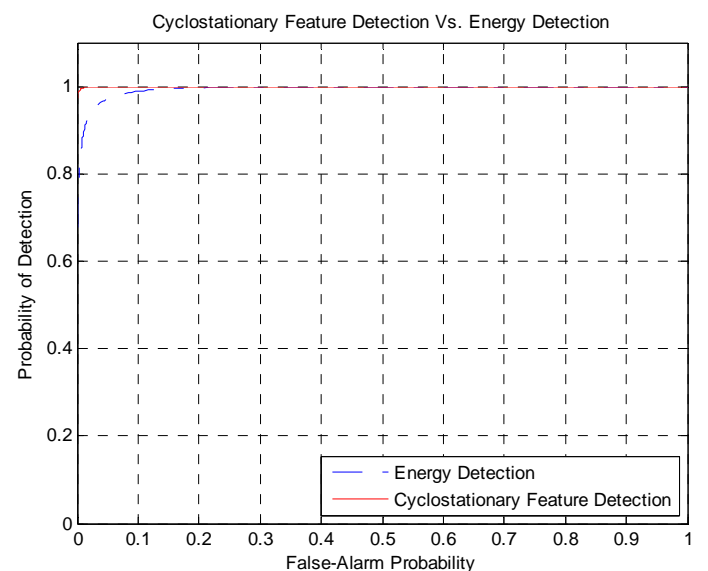

Gambar 8. Kinerja dengan SNR $=11 \mathrm{~dB}$

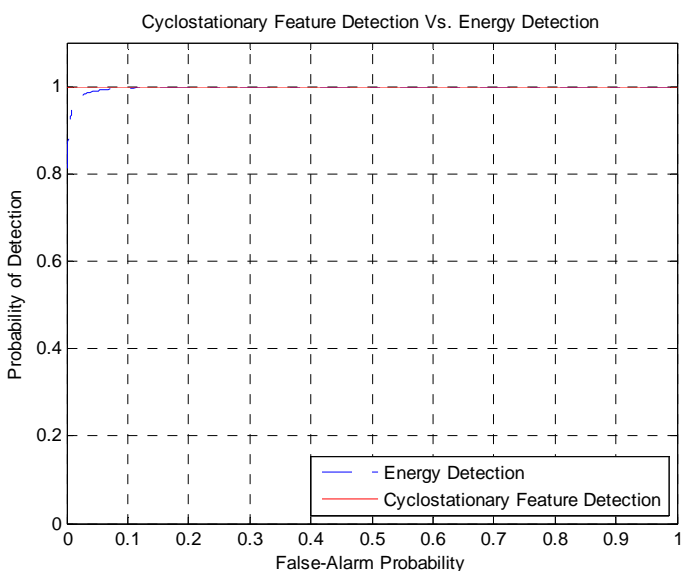

Gambar 9. Kinerja dengan SNR $=12 \mathrm{~dB}$

Dari gambar 8 dan gambar 9 dapat diketahui bahwa kinerja dari Cyclostationary Feature Detection sudah memiliki nilai Probability of Detection (Pd) sebesar 0,99 untuk nilai Probability of False Alarm (PFA) sebesar 0 pada saat nilai SNR $=12 \mathrm{~dB}$. Sedangkan kinerja dari Energy Detection untuk nilai Probability of False Alarm (PFA) sebesar 0 memiliki nilai Probability of Detection (Pd) masih sebesar 0,81. Sehingga dapat disimpulkan bahwa Cyclostationary Feature Detection memiliki nilai kinerja minimum untuk mendapatkan Probability of Detection (Pd) sebesar 1 dengan nilai Probability of False Alarm (PFA) sebesar 0 yaitu pada saat memiliki nilai $S N R \approx 12 \mathrm{~dB}$.

\subsection{Kinerja Cyclostationary Feature Detection Vs. Energy Detection dengan Fungsi SNR}

Gambar berikut ini akan menunjukkan grafik kinerja dari Cyclostationary Feature Detection dibandingkan dengan grafik kinerja dari Energy Detection dilihat dari fungsi Signal to Noise Ratio (SNR) dengan nilai Probability of False Alarm (PFA) sebesar 0,0001. Penggunaan nilai Probability of False Alarm (PFA) sebesar 0,0001 berdasarkan pada beberapa penelitian sebelumnya yang selalu menggunakan nilai yang sama sebagai pembanding dan hasilnya juga dapat diamati dengan jelas secara grafik karena nilainya tidak terlalu kecil dan tidak terlalu besar.

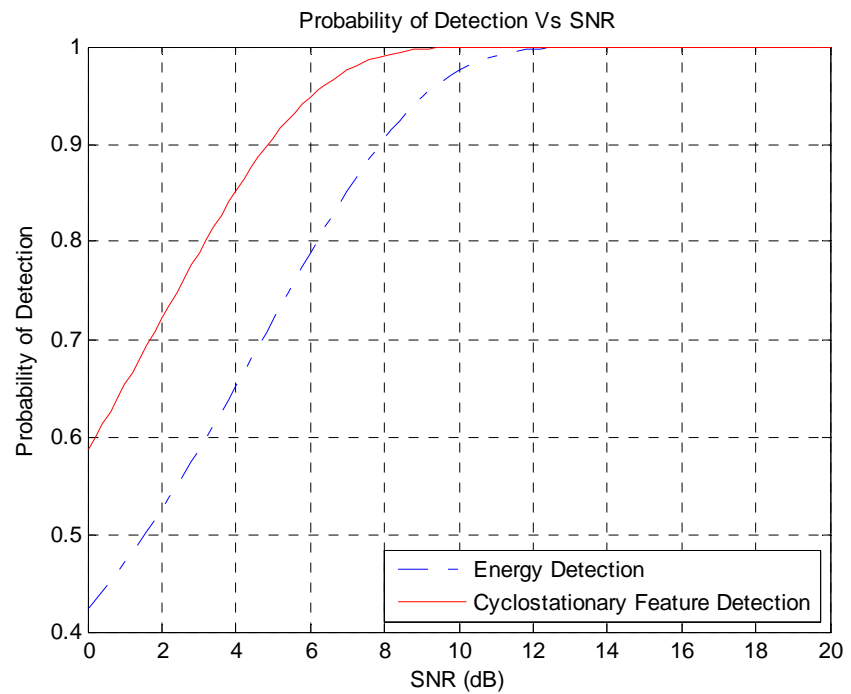

Gambar 10. Probability of False Alarm (PFA) sebesar 0,0001 
Dari gambar 10 dapat diketahui bahwa kinerja Cyclostationary Feature Detection lebih baik daripada kinerja Energy Detection. Dapat diambil contoh pada nilai SNR $=6 \mathrm{~dB}$, nilai Probability of Detection (Pd) dari Cyclostationary Feature Detection sebesar 0,94 sedangkan nilai Probability of Detection (Pd) dari Energy Detection masih sebesar 0,78. Kemudian pada nilai SNR $\approx 11 \mathrm{~dB}$, nilai Probability of Detection (Pd) dari Cyclostationary Feature Detection sebesar 0,9999 sedangkan nilai Probability of Detection (Pd) dari Energy Detection masih sebesar 0,9906.

Dari beberapa perbandingan tersebut maka dapat disimpulkan bahwa kinerja Cyclostationary Feature Detection selalu lebih baik daripada Energy Detection untuk setiap nilai Signal to Noise Ratio (SNR) ataupun untuk setiap nilai Probability of False Alarm (PFA).

\subsection{Kesimpulan}

\section{KESI MPULAN DAN SARAN}

Berdasarkan pada analisis hasil simulasi matlab yang berupa grafik pada bagian sebelumnya, maka dapat diperoleh kesimpulan sebagai berikut :

1. Kinerja Cyclostationary Feature Detection lebih baik daripada kinerja dari Energy Detection dilihat dari fungsi Probability of False Alarm (PFA) karena pada nilai Signal to Noise Ratio (SNR) sebesar $-15 \mathrm{~dB}$ hingga $5 \mathrm{~dB}$, nilai Probability of Detection (Pd) dari Cyclostationary Feature Detection selalu berada diatas Energy Detection.

2. Kinerja Cyclostationary Feature Detection lebih baik daripada kinerja dari Energy Detection dilihat dari fungsi Signal to Noise Ratio (SNR) karena pada nilai SNR $\approx 11$ $\mathrm{dB}$, nilai Probability of Detection (Pd) dari Cyclostationary Feature Detection sebesar 0,9999 sedangkan nilai Probability of Detection (Pd) dari Energy Detection masih sebesar 0,9906.

3. Cyclostationary Feature Detection akan mencapai nilai Probability of Detection (Pd) yang maksimal dengan nilai Signal to Noise Ratio (SNR) sebesar $\approx 12 \mathrm{~dB}$.

4. Secara keseluruhan dapat disimpulkan bahwa radio kognitif memiliki metode terbaik dalam melakukan teknik spectrum sensing yaitu Cyclostationary Feature Detection.

\subsection{Saran}

Mengingat pada penelitian ini simulasi hanya terhadap fungsi Probability of False Alarm (PFA) dan Signal to Noise Ratio (SNR), maka pada penelitian selanjutnya diharapkan bisa menggunakan parameter fungsi yang lain seperti Probability Miss Detection.

\section{DAFTAR RUJ UKAN}

Verma, Pradeep Kumar. (2012). Performance analysis of Energy detection, Matched filter detection \& Cyclostationary feature detection Spectrum Sensing Techniques, Vol. 2, No. 5, pp : 1296-1301.

Subhedar, Mansi and Gajanan Birajdar. (2011). Spectrum Sensing Techniques in Cognitive Radio Networks: a Survey. India: Department of Electronics and Telecommunication Engineering, SIES Graduate School of Technology, Navi Mumbai.

Alaydrus, Mudrik. (2010). Cognitif Radio : Sistem Radio Cerdas. Jakarta : Magister Teknik Elektro, Universitas Mercu Buana. 
Kim, Hyung Seok and Waleed Ejaz etc. (2013). I3S : Intelligent spectrum sensing scheme for cognitive radio networks, pp : 1499-1687.

Sood, Vishakha and Manwinder Singh. (2011). On the Performance of Detection based Spectrum Sensing for Cognitive Radio. India : Rayat Institute of Engineering and Information Technology, Railmajra, Punjab. 